\title{
Cardioesophageal Cancer: Best Treatment Strategies
}

\author{
Oleg Kshivets*
}

Department of Thoracic Surgery, Klaipeda University Hospital, Klaipeda, Lithuania

\begin{abstract}
Objective: We examined the clinicomorphologic factors associated with the low- and high-risk of generalization of cardioesophageal cancer (CEC) (T1-4N0-2M0) after complete (R0) esophagogastrectomies (EG) through left thoracoabdominal incision.

Methods: We analyzed data of 175 consecutive CEC patients (CECP) (age $=55.3 \pm 8.7$ years; tumor size $=6.9 \pm 3.3 \mathrm{~cm}$ ) radically operated and monitored in 1975-2008 (males $=132$, females $=43$; combined EG with resection of pancreas, liver, diaphragm, colon transversum, lung, trachea, pericardium, splenectomy - 71; lymphadenectomy D2 - 98, D3-D4 77; esophagogastroanastomosis - 98, esophagoenteroanastomosis - 77; adenocarcinoma - 112, squamous cell carcinoma 58, mix - 5; T1 - 24, T2 - 38, T3 - 66, T4 - 47; N0 - 70, N1 - 22, N2 - 83; G1 - 52, G2 - 34, G3 - 89; surgery alone - 128; surgery and adjuvant chemoimmunotherapy-AT: 5FU + thymalin/taktivin, 5-6 cycles - 47 CECP).

Variables selected for 5-year survival (5YS) study were input levels of 45 blood parameters, sex, age, TNMPG, cell type, tumor size. Survival curves were estimated by the Kaplan-Meier method. Differences in curves between groups of CECP were evaluated using a log-rank test. Multivariate Cox modeling, multi-factor clustering, structural equation modeling, Monte Carlo, bootstrap simulation and neural networks computing were used to determine any significant dependence.

Results: For total of 175 CECP overall life span (LS) was 1381.6 \pm 1486.7 days, (median - 723 days) and cumulative 5YS reached $36.1 \%$, 10 years - 26.6\%. 53 CECP lived more than 5 years without CEC progressing. 104 CECP died because of CEC during the first 5 years after surgery. $5 \mathrm{YS}$ of CECP was superior significantly after AT (69.9\%) compared with surgery alone $(26.6 \%)(\mathrm{P}=0.000$ by log-rank test). Cox modeling displayed that 5 YS of CECP $(\mathrm{n}=175)$ after complete EG significantly depended on: phase transition (PT) early-invasive CEC, PT N0-N12, AT, age, T, tumor growth, Rh-factor, blood cell subpopulations, cell ratio factors $(\mathrm{P}=0.000-0.047)$. Neural networks computing, genetic algorithm selection and bootstrap simulation revealed relationships between 5YS and early-invasive CEC (rank =1), PT N0-N12 $($ rank $=2)$, AT (rank = 3), T (4), gender (5), prothrombin index (6), weight (7), glucose (8), age (9), coagulation time (10), eosinophils/cancer cells (11), erythrocytes/cancer cells (12), hemorrhage time (13), protein (14), Hb (15), segmented neutrophils/cancer cells (16), stab neutrophils/cancer cells (17). Correct prediction of 5YS was $100 \%$ by neural networks computing (error $=0.0009 \mathrm{e}-12$; urea under ROC curve $=1.0$ ).

Conclusions: Best treatment strategies for CECP are: 1) screening and early detection of CEC; 2) availability of very experienced thoracoabdominal surgeons because of complexity of radical procedures; 3) aggressive en block surgery and adequate abdominal, mediastinal, cervical lymphadenectomy for completeness; 4) high-precision prediction; 5) adjuvant chemoimmunotherapy for CECP with unfavorable prognosis.
\end{abstract}

\section{INTRODUCTION}

The problem of cardioesophageal cancer (CEC) took on special significance last years. This is caused by 300-500\% growth of this fatal disease during last 30 years, having character of a pandemic in the USA, European Union, Russia, Japan, etc. $[1,2]$. Today CEC takes the 6th place in cancer mortality in the world. It ranks special position in medicine and represents a fundamental challenge for surgery. The real 5-year survival (5YS) across all stages of CEC is approximately $5-10 \%$ in the USA and Europe [2, 3]. Disputes begin already at the definition of CEC concept. Actually, valid classification of $\mathrm{CEC}$ is absent, as a result of a cardia cancer with primary spreading on the esophagus classifies as an esophageal cancer, and with expansion to the stomach - as a

*Address correspondence to this author at the Thoracic Surgery Department, Klaipeda University Hospital, Vingio: 16, P/D 1017, Klaipeda, LT95188, Lithuania; Tel: (370)60878390; E-mail: kshivets003@yahoo.com

1876-5335/09 gastric cancer [4]. Formal definition of cardia, given by $\mathrm{J}$. Siewert, as on $1 \mathrm{~cm}$ is higher and $2 \mathrm{~cm}$ below gastroesophageal junction, served by the basis for his classification of CEC as the tumors located on $5 \mathrm{~cm}$ is higher and below anatomic cardia, in any way does not reflect the features of this disease $[5,6]$. And they are rather essential. The prognosis of CEC is much worse significantly, than esophageal cancer or gastric cancer alone, that is caused by extreme aggressive behavior and very fast local and system dissemination of CEC since this oncopathology is located on the border of two cavities (abdomen and thorax) and two mucous coats (esophagus and stomach). Agreeably, lymph outflow occurs in two regions (abdominal and mediastinal) (Fig. 1). Infiltration of cancer cells upwards on the gullet can differ on 10-12 cm from visible tumor burdens, achieving sometimes till cervical part of esophagus [7]. In view of close mutual relation of cardioesophageal junction to several organs (stomach, gullet, liver, pancreas, lien, diaphragm, lung, pericardium, colon transversum) completeness of procedures for local advanced CEC can be achieved only by multiorgans 
resections. Therefore treatment of tumors for this localization is one of the most difficult and disputable sections of thoracoabdominal surgery [3]. Extensive abdominal (D2D4), mediastinal, and, in some cases, cervical lymphadenectomy (2-3 folds) is the cornerstone of the radical esophagogastrectomy [8]. It has not only medical and diagnostic, but also prognostic value. All this demands from the surgeon of virtuosous techniques, huge experience, force and endurance. That is why the surgery of CEC always remains the privilege of a narrow circle of the best surgeons of the world, which deficiency accrues every year. And finally, usually the basic attention during analysis of CEC was given to the nearest postoperative results in view of complexity of surgical interventions and features of postoperative monitoring of patients, and the remote period remains in a shade. Considering the premises, we analyzed the long time results of treatment of patients with CEC (CECP) after radical (R0) esophagogastrectomies through the left thoracoabdominal incision (Garlock operation). We developed best treatment strategies that incorporate bolus chemotherapy and immunotherapy after radical, aggressive en-block surgery and adequate abdominal, mediastinal and cervical lymph node dissection.

\section{PATIENTS AND METHODS}

We performed a review of prospectively collected database of European patients undergoing the complete (R0) esophagogastrectomy for CEC between 1975 and 2008. 175 consecutive CECP (male - 132, female - 43; age = 55.3 \pm 8.7 years, tumor size $=6.9 \pm 3.3 \mathrm{~cm})($ mean \pm standard deviation) entered this trial. Patients were not considered eligible if they had stage IV (nonregional lymph nodes metastases and distant metastases), previous treatment with chemotherapy, immunotherapy or radiotherapy or if there were two primary tumors at the time of diagnosis. CECP after nonradical procedures and patients, who died postoperatively, were excluded to provide a homogeneous patient group. The preoperative staging protocol included clinical history, physical examination, complete blood count with differentials, biochemistry and electrolyte panel, chest X-rays, röntgenoesophagogastroscopy, computed tomography scan of thorax, abdominal ultrasound, fibroesophagogastroscopy, electrocardiogram. Computed tomography scan of abdomen, liver and bone radionuclide scan were performed whenever needed. Mediastinoscopy was not used. All CECP were diagnosed with histologically confirmed CEC. All had measurable tumor and ECOG performance status 0 or 1. Before any treatment each patient was carefully examined by a medical panel composed of thoracic surgeon, chemotherapeutist, radiologist and gastroenterologist to confirm the stage of disease. All patients signed a written informed consent form approved by the local Institutional Review Board.

The initial treatment was started with surgery. We are basic supporters of Garlock's operation through left thoracoabdominal incision for CEC as more convenient and less traumatic, than Lewis's operation (Figs. 2, 3). Conclusive advantages of left thoracoabdominal approach are unsurpassed conveniences for combined multiorgans resections, extensive lymphadenectomy and exact correlation of length of a gastric tube or jejunum with the level of anastomosis [912]. At this procedure we removed the most part of stomach

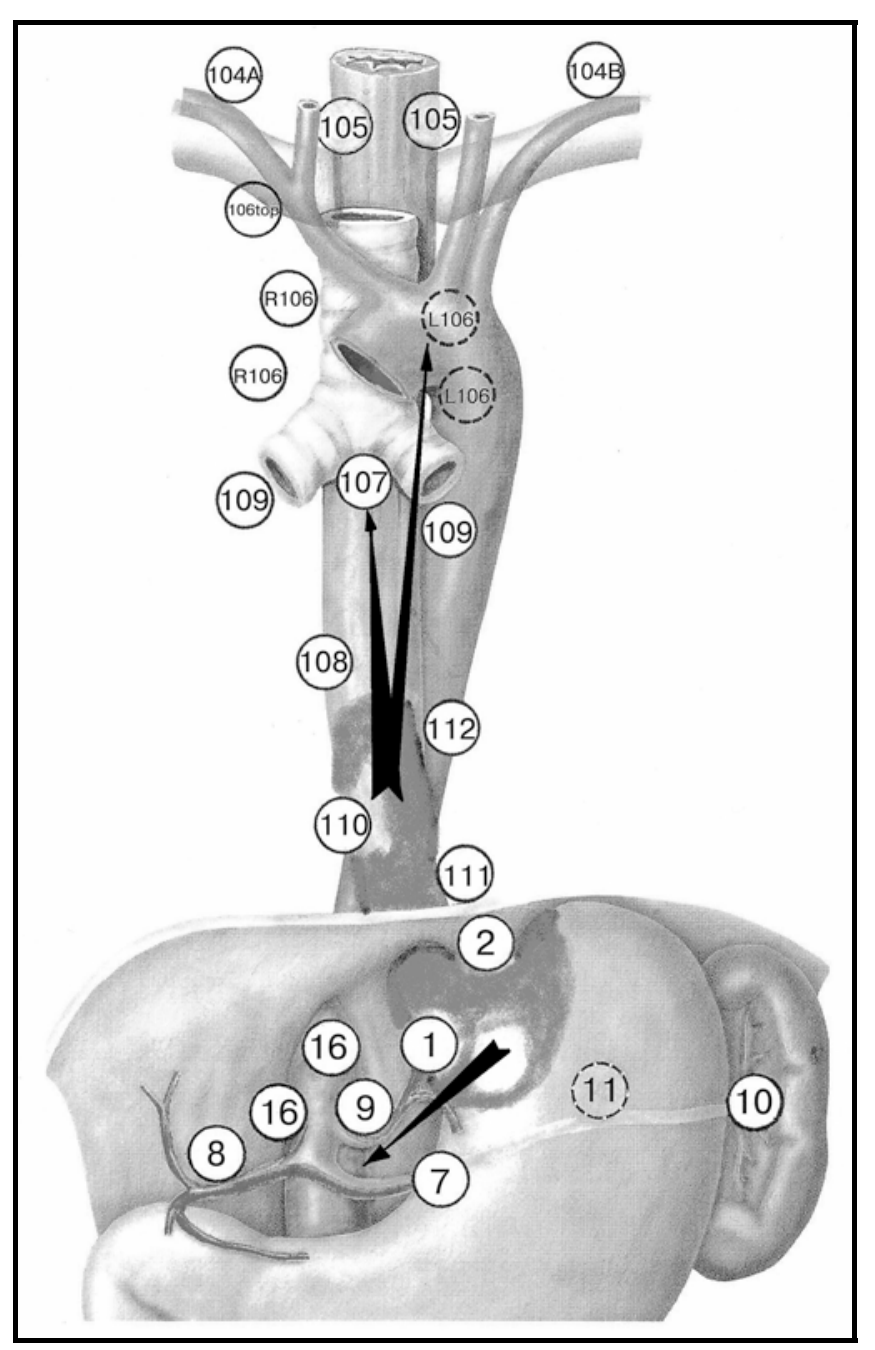

Fig. (1). Scheme of lymph node metastasis for cardioesophageal cancer: 1 - right paracardial; 2 - left paracardial; 7 - along left gastric artery; $\mathbf{8}$ - along common hepatic artery; $\mathbf{9}$ - along celiac trunk; $\mathbf{1 0}$ - lien hilar; 11 - along lienal artery; 16 - aortocaval and paraaortal abdominal; 104a - right supraclavicular; 104b - left supraclavicular; 105 - upper paraesophageal; R106 - right paratracheal; L106 - left paratracheal; 107 - bifurcational; 108 - middle paraesophageal; 109 - lung hilar; 110 - lower paraesophageal; 111 - diaphragmatic; 112 - paraaortal thoracic.

with preservation of right gastroepiploic vessels or total stomach with an esophagus on 6-12 cm above proximal tumor burden with intraoperative express-histology for clearance without fail, minor and major omentum, and also lymph nodes on the both sides of a diaphragm (lymph nodes along of celiac trunk, common hepatic artery, splenic artery toward the splenic hilum, paracardial, paraesophageal, sub- and supradiaphragmatic, mediastinal, bifurcational, paraaortal and aortocaval lymph nodes) (Figs. 1, 3). The left gastric artery was always transected at its origin and remained with the specimen. The present analysis was restricted to CECP with complete resected tumors with negative surgical resection margin and with N0-2 lymph nodes. Patients with the CEC infiltration till upper third of esophagus had an additional formal extended mediastinal lymphadenectomy comprising all nodes at the tracheal bifurcation along the left and right main stem bronchi, aorta window, the upper mediastinal compartment, and along the left recurrent nerve. A system- 


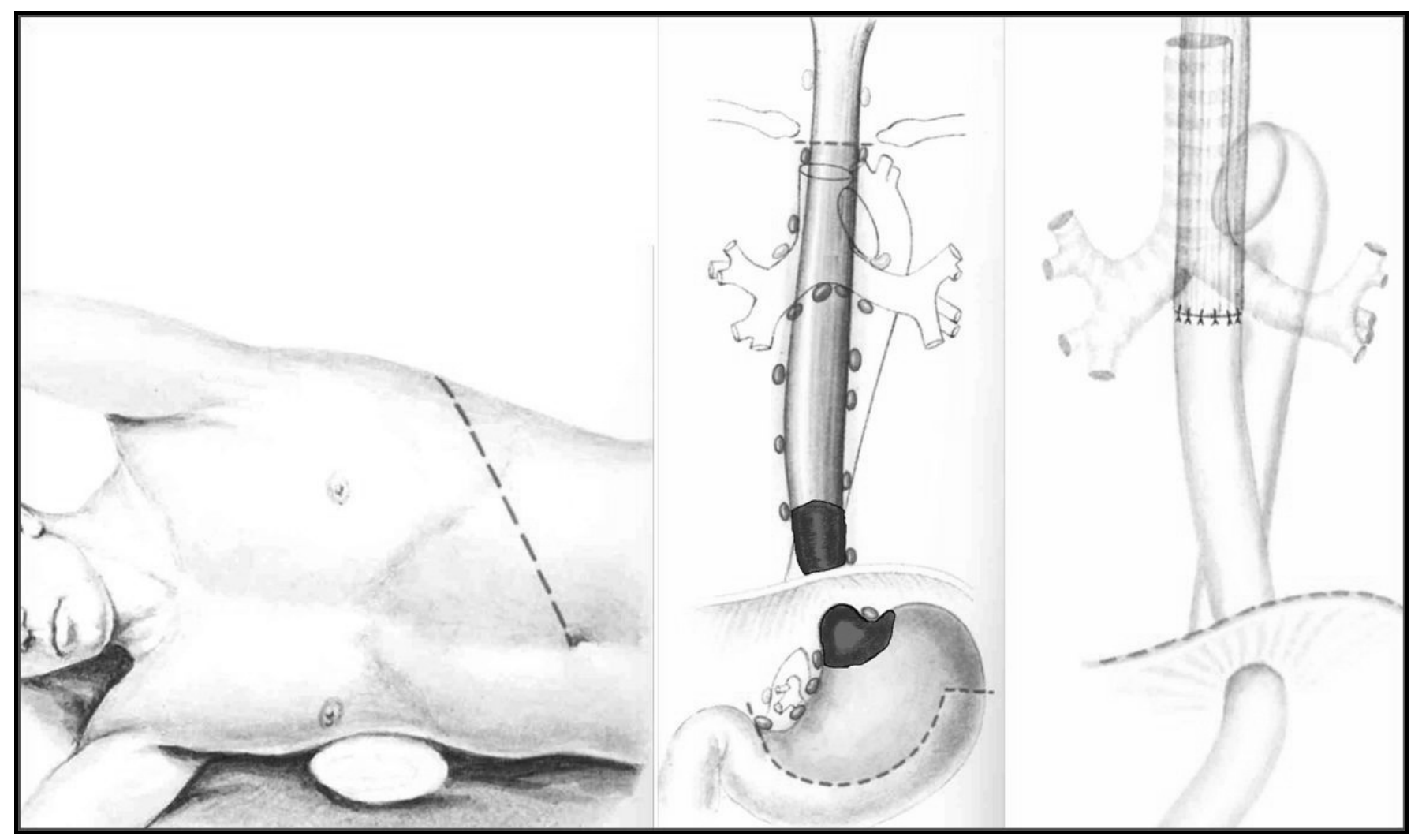

Fig. (2). Scheme of left thoracoabdominal incision and Garlock procedure.

atic cervical lymphadenectomy was performed routinely for CECP with neck anastomosis. 98 patients underwent lymph nodal D2-dissection (in terms of gastric cancer surgery). Extensive lymph nodal D3-D4-dissection was performed in 77 CECP. Routine two-field lymphadenectomy (in terms of esophageal surgery) was performed in 133, three-field - in 42. Complete surgical procedure consisted of esophagogastrectomy with one-stage intrapleural esophagogastrostomy or esophagoenterostomy in 133 and with anastomosis on the neck - in 42. CEC was localized till lower third of esophagus in 85, middle third - in 61, upper third - in 29. Among these, 71 CECP underwent combined esophagogastrectomy with multiorgans resections of pancreas, liver, diaphragm, colon transversum, lung, trachea, pericardium, splenectomy. Esophagogastric and esophagojejunic anastomosis were carried out manually as an inktype "end to end". For total gastrectomy we added lymph node dissection of subpyloric, lienal, retropancreatic, hepatoduodenal, aortocaval, supramesenteric, mesocolonic lymph nodes (Fig. 1). Complete resection (R0) was defined as removal of the primary tumor and all accessible tissues, lymph nodes, with no residual tumor left behind (resection of all macroscopic tumor and resection margins free of tumor at microscopic analysis).

All CECP were postoperatively staged according to the TNMG-classification. Histological examination showed adenocarcinoma in 112, squamous cell carcinoma - in 58 and mixed carcinoma - in 5 patients. The pathological $\mathrm{T}$ stage was $\mathrm{T} 1$ in $24, \mathrm{~T} 2$ - in $38, \mathrm{~T} 3$ - in $66, \mathrm{~T} 4$ - in 47 cases; the pathological N stage was $\mathrm{N} 0$ in $70, \mathrm{~N} 1$ - in $22, \mathrm{~N} 2$ - in 83 patients. The tumor differentiation was graded as G1 in 52, G2 - in 34, G3 - in 89 cases. After surgery postoperative chemoimmunotherapy was accomplished in CECP with ECOG performance status 0 or 1 .

All patients (175 CECP) were divided randomly between the two protocol treatment: 1) surgery and adjuvant chemoimmunotherapy (47 CECP - group A); 2) surgery alone without any adjuvant treatment (128 CECP - group B) - the control group.

Forty-seven CECP received adjuvant chemoimmunotherapy which consisted of chemoimmunotherapy (5-6 cycles) (group A). 1 cycle of bolus chemotherapy was initiated 3-5 weeks after complete esophagogastrectomies and consisted of fluorouracil $500 \mathrm{mg} / \mathrm{m} 2$ intravenously for 5 days. Immunotherapy consisted thymalin or taktivin $20 \mathrm{mg}$ intramuscularly on days 1, 2, 3, 4 and 5. These immunomodulators produced by Pharmaceutics of Russian Federation (Novosibirsk) and approved by Ministry of Health of Russian Federation. Thymalin and taktivin are preparations from calf thymus, which stimulate proliferation of blood T-cell and B-cell subpopulations and their response [13]. The importance must be stressed of using immunotherapy in combination with chemotherapy, because immune dysfunctions of the cellmediated and humoral response were induced by tumor, surgical trauma and chemotherapy [14]. Such immune deficiency induced generalization of CEC and compromised the long-term surgery result. In this sense, immunotherapy may have shielded the patient from adverse side effects of treatment. During chemoimmunotherapy antiemetics were administered. Gastrointestinal side effects, particularly nausea and vomiting, were mild, and chemoimmunotherapy was generally well tolerated. Severe leukopenia, neutropenia, anemia and trombocytopenia occurred infrequently. There were no treatment-related deaths. 


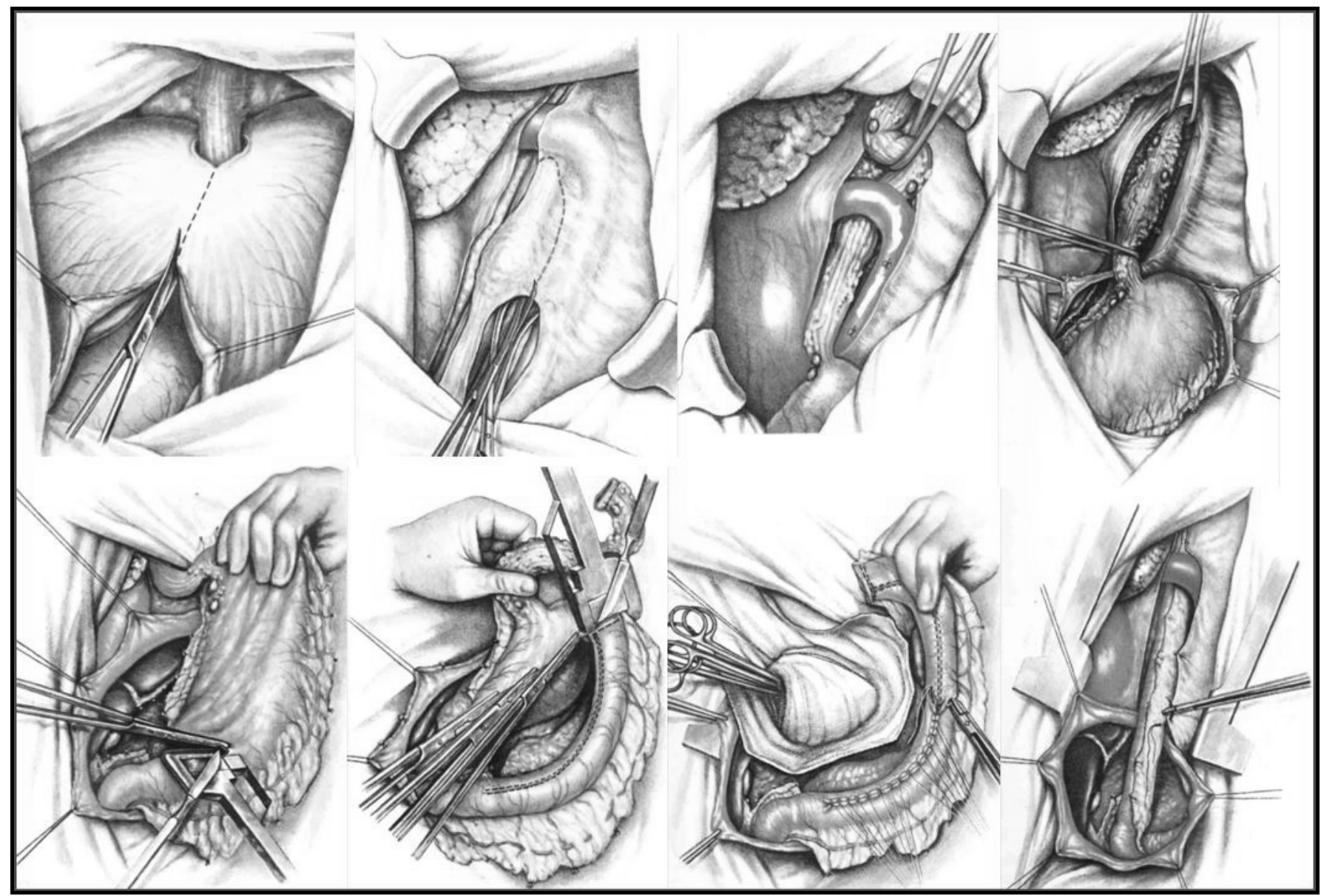

Fig. (3). Our methodology of esophagogastrectomy through left thoracoabdominal approach.

A follow-up examination was, generally, done every 3 month for the first 2 years, every 6 month after that and yearly after 5 years, including a physical examination, a complete blood count, blood chemistry, and chest roentgenography. Fibroesophagogastroscopy was done every 6 months for the first 3 years. Zero time was the data of surgical procedures. No one was lost during the follow-up period and we regarded the outcome as death through personal knowledge, physician's reports, autopsy or death certificates. Survival time (days) was measured from the date of surgery until death or the most-recent date of follow-up for surviving patients.

Variables selected for 5YS and life span (LS) study were the input levels of 45 blood parameters, sex, age, TNMG, cell type, and tumor size. Survival curves were estimated by the Kaplan-Meier method. Differences in curves between groups of CECP were evaluated using a log-rank test. Multivariate proportional hazard Cox regression, structural equation modeling (SEPATH), Monte Carlo simulation, bootstrap simulation and neural networks computing were used to determine any significant dependence [15-21]. Neural networks computing, system, biometric and statistical analyses were conducted using CLASS-MASTER program (Stat Dialog, Inc., Moscow, Russia), SANI program (Stat Dialog, Inc., Moscow, Russia), DEDUCTOR program (BaseGroup Labs, Inc., Riazan, Russia), SPSS (SPSS Inc., Chicago, IL, USA), STATISTICA and STATISTICA Neural Networks program (Stat Soft, Inc., Tulsa, OK, USA), MATHCAD (MathSoft,
Inc., Needham, MA, USA), SIMSTAT (Provalis Research, Inc., Montreal, QC, Canada). All tests were considered significant if the resulting $\mathrm{P}$ value was less than 0.05 .

\section{RESULTS}

For the entire sample of 175 patients overall LS was $1381.6 \pm 1486.7$ days (mean \pm standard deviation) $(95 \% \mathrm{CI}$, 1159.8-1603.4 days; median $=723$ ). General cumulative 5YS reached 36.1\%, 10-year survival - 26.6\%. 61 CECP (34.9\%) were alive till now, 53 CECP (30.3\%) lived more than 5 years (LS $=3212.7 \pm 1512.0$ days) without any features of CEC progressing. 104 CECP (59.4\%) died because of generalization during the first 5 years after surgery (LS = $587.3 \pm 316.8$ days) (Fig. 4).

It is necessary to pay attention to the two very important prognostic phenomenas. First, we found $100 \%$ YYS for CECP with early cancer $(\mathrm{T} 1 \mathrm{~N} 0, \mathrm{n}=18)$ versus $28.4 \%$ for other CECP $(\mathrm{n}=157)$ after esophagogastrectomies $(\mathrm{P}=$ 0.000 by log-rank test) (Fig. 5). Early CEC was defined, based on the final histopathologic report of the resection specimen, as tumor limited to the mucosa or submucosa and not extending into the muscular wall of the cardioesophageal junction, up to $2 \mathrm{~cm}$ in diameter with N0 [12]. All patients with stage T1N0 did not receive adjuvant chemoimmunotherapy. Correspondingly, the overall 10-year survival for CECP with the early cancer was $92.6 \%$ and was significantly better compared to $18.4 \%$ for others patients $(\mathrm{P}=0.000)$. 


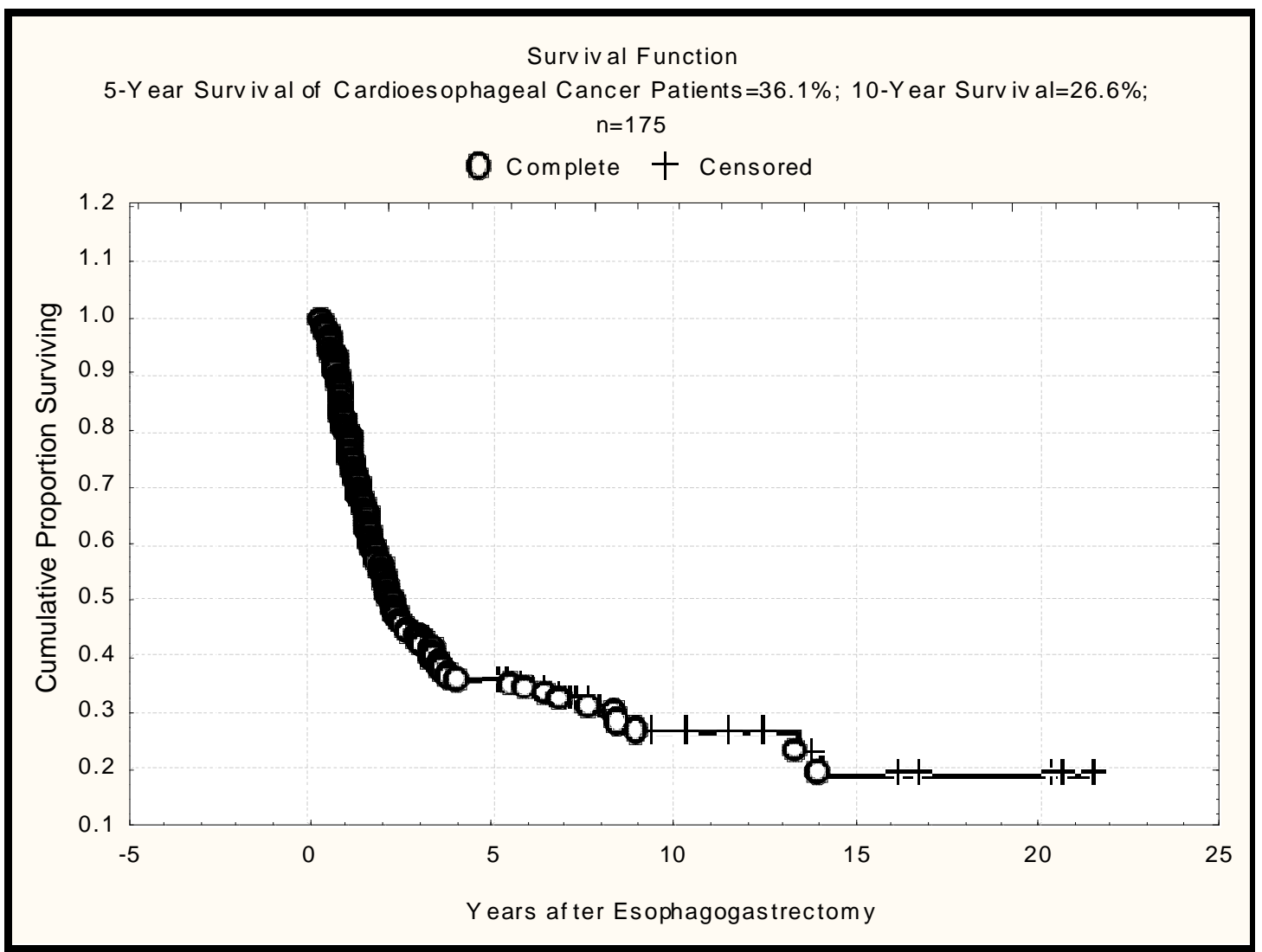

Fig. (4). General cumulative survival of CECP with stage T1-4N0-2M0, n = 175 after radical esophagogastrectomies: cumulative 5-year survival $=36.1 \%, 10$-year survival $=26.6 \%$.

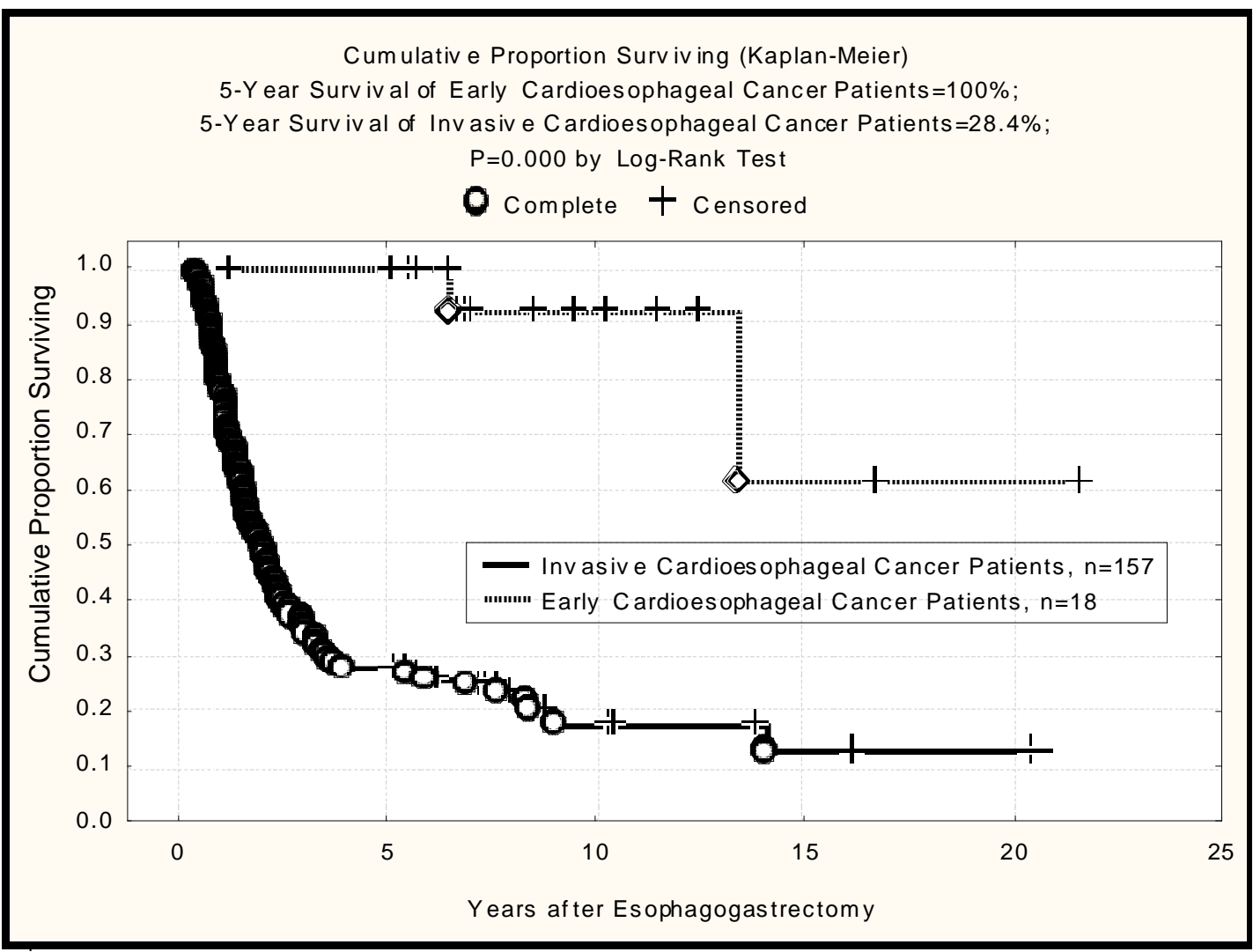

Fig. (5). Survival of CECP with early cancer $(n=18)$ was significantly better compared with invasive cancer $(n=157)(P=0.000$ by $\log$ rank test). 


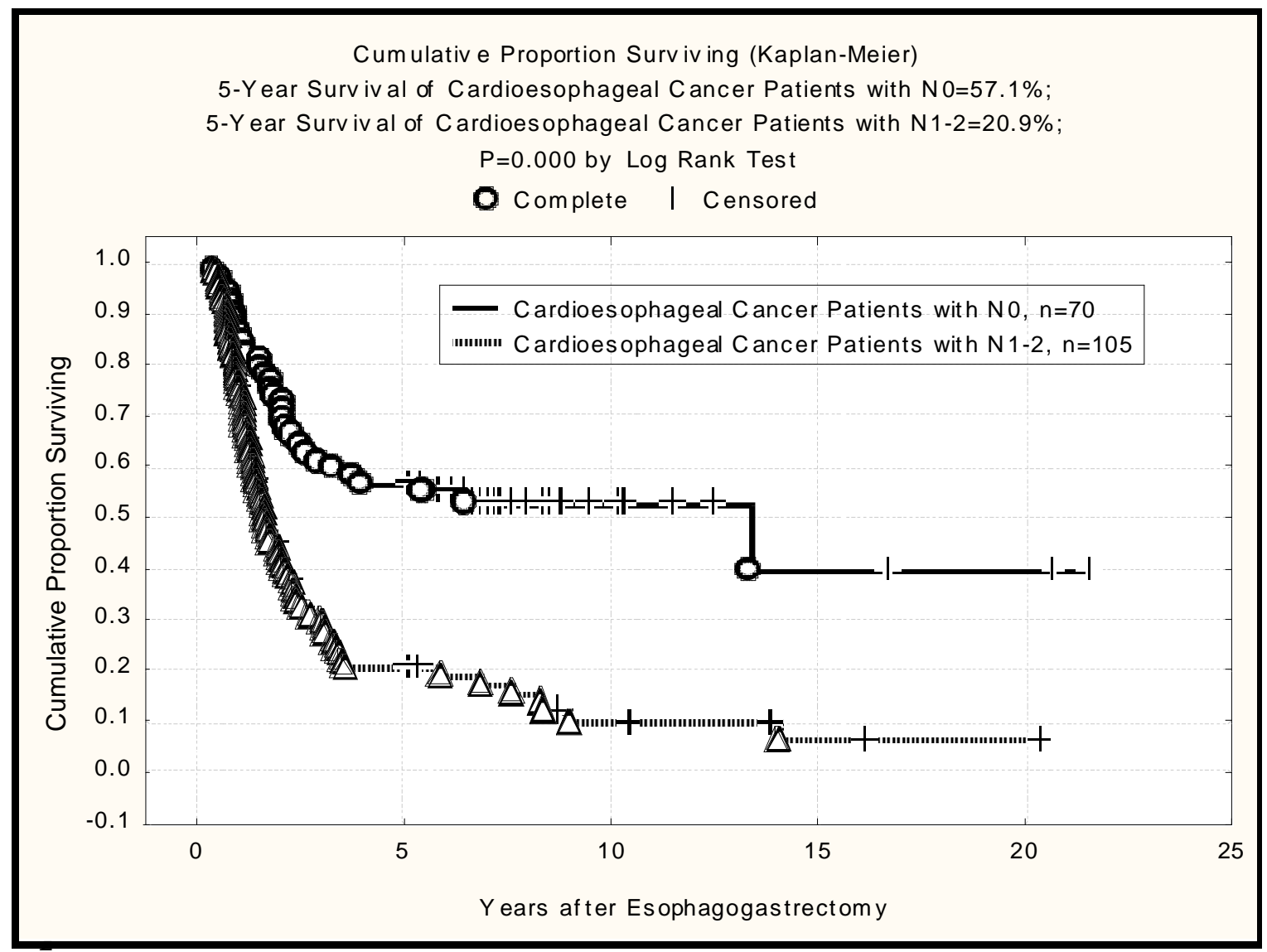

Fig. (6). Survival of CECP with N0 $(n=70)$ was significantly better compared with N1-2 metastases $(n=105)(P=0.000$ by log-rank test $)$.

Second, we observed relative good 5YS of CECP with N0 $(57.1 \%, \mathrm{n}=70)$ as compared with $5 Y$ S of CECP with N1-N2 $(20.9 \%, \mathrm{n}=107)$ after radical procedures $(\mathrm{P}=0.000$ by log-rank test) (Fig. 6). Accordingly, the overall 10-year survival for CECP with N0 reached 53\% and was significantly superior compared to $10.4 \%$ for CECP with lymph node metastasis. Owing to the relatively high frequency of distant failure after surgical resection of CEC with lymph nodal metastasis, it has been generally accepted that nodal metastasis would be an indicator of systemic metastasis $[12,14]$. Consequently, at least two separate subsets of patients can be defined from present study: those with N0 status and those with N1-2 involvement. These factors must be taken into account in system analysis of CECP survival and are particularly cogent when attempting to translate obtained results into best treatment strategies.

For 47 CECP in adjuvant chemoimmunotherapy arm (group A), overall LS was 1844.7 \pm 1874.6 days and for 128 CECP in the control (group B), overall LS was $1211.5 \pm$ 1283.3 days $(\mathrm{P}=0.000$ by log-rank). The overall 5YS of CECP for group A reached $69.9 \%$ and was significantly superior compared to $26.6 \%$ for group $\mathrm{B}(\mathrm{P}=0.000)$ (Fig. 7).

All parameters were analyzed in a multivariate $\mathrm{Cox}$ model. In accordance with this Cox model (global $\chi^{2}=$ 126.03; $\mathrm{Df}=25$; $\mathrm{P}=0.000$ ), the nineteen variables significantly explained survival of CECP after surgery: phase transition early---invasive cancer, phase transition N0---N1-N2, tumor growth, T1-4, adjuvant chemoimmunotherapy, age, blood cell subpopulations and cell ratio factor (ratio between blood cell subpopulations and cancer cell population) (Table 1).

For comparative purposes, clinicomorphological variables of CECP ( $\mathrm{n}=157$ : 53 5-year survivors and 104 losses) were tested by neural networks computing (4-layer perceptron) (Fig. 8). To obtain a more exact analysis 18 patients being alive less than 5 years after radical procedures without relapse were excluded from the sample. Multilayer perceptron was trained by Levenberg-Marquardt method. Obviously, analyzed data provide significant information about CEC prediction. High accuracy of classification - 100\% (5year survivors $v s$ losses) was achieved in analyzed sample (baseline error $=0.0009 \mathrm{e}-12$, are under ROC curve $=1.0$ ). In other words it remains formally possible that reviled the seventeen factors might predate neoplastic generalization: phase transition early---invasive CEC (rank $=1$ ), phase transition N0---N1-2 (rank $=2)$, adjuvant chemoimmunotherapy (rank = 3), T1-4 (4), gender (5), prothrombin index (6), weight (7), glucose (8), age (9), coagulation time (10), ratio eosinophils/cancer cells (11), erythrocytes/cancer cells (12), hemorrhage time (13), protein (14), hemoglobin (15), segmented neutrophils/cancer cells (16), stab neutrophils/cancer cells (17) (Table 2). Genetic algorithm selection and bootstrap simulation confirmed significant dependence between 5YS of CECP after radical procedures and all recognized variables (Tables 3, 4). Moreover, bootstrap simulation confirmed the paramount value of cell ratio factors and the two very special patient's homeostasis states: patients with early CEC and N1-2 metastasis. 


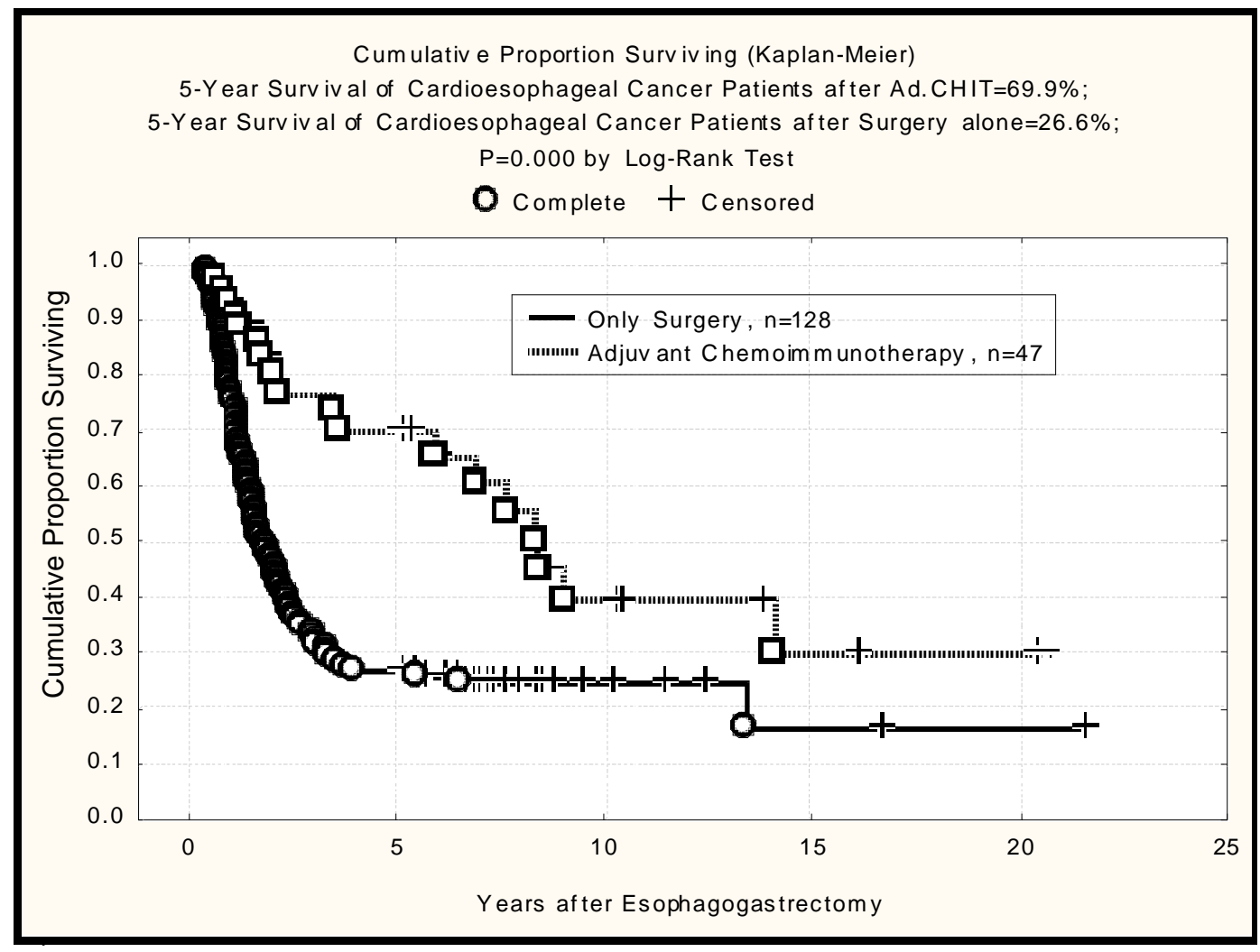

Fig. (7). Survival of CECP after esophagogastrectomies in group A (adjuvant chemoimmunotherapy) $(\mathrm{n}=47)$ and $B$ (surgery alone) ( $\mathrm{n}=$ 128). 5-year survival of CECP in group A (69.9\%) was significantly better compared with group B $(26.6 \%)(\mathrm{P}=0.000$ by log-rank test).

Table 1. Results of Multivariate Proportional Hazard Cox Regression Modeling in Prediction of CECP Survival After Esophagogastrectomies $(n=175)$

\begin{tabular}{|l|c|c|c|}
\hline \multicolumn{1}{|c|}{ Variables in the Equation } & Wald & df & P \\
\hline \hline Phase Transition "Early---Invasive CEC" & 3.962 & 1 & 0.047 \\
Phase Transition "NO---N1-2" & 11.537 & 1 & 0.001 \\
$\mathrm{~T}$ & 7.957 & 3 & 0.047 \\
$\mathrm{~T}(1)$ & 7.601 & 1 & 0.006 \\
$\mathrm{~T}(2)$ & 2.616 & 1 & 0.106 \\
$\mathrm{~T}(3)$ & 0.604 & 1 & 0.437 \\
Age & 8.358 & 1 & 0.004 \\
Adjuvant Chemoimmunotherapy & 44.417 & 1 & 0.000 \\
Erythrocytes/Cancer Cells & 7.321 & 1 & 0.007 \\
Leucocytes/Cancer Cells & 6.477 & 1 & 0.011 \\
Eosinophils/Cancer Cells & 3.604 & 1 & 0.058 \\
Stab Neutrophils/Cancer Cells & 4.281 & 1 & 0.039 \\
Segmented Neutrophils/Cancer Cells & 4.753 & 1 & 0.029 \\
Lymphocytes/Cancer Cells & 3.108 & 1 & 0.078 \\
Healthy Cells/Cancer Cells & 6.273 & 1 & 0.012 \\
Segmented Neutrophils (\%) & 8.939 & 1 & 0.003 \\
Monocytes (\%) & 9.349 & 1 & 0.002 \\
Monocytes (abs) & 11.445 & 1 & 0.001 \\
Stab Neutrophils (tot) & 7.845 & 1 & 0.005 \\
Leucocytes (tot) & 5.683 & 1 & 0.017 \\
Eosinophils (tot) & 4.038 & 1 & 0.044 \\
Lymphocytes (tot) & 3.264 & 1 & 0.071 \\
Monocytes (tot) & 3.674 & 1 & 0.055 \\
Tumor Growth & 17.210 & 2 & 0.000 \\
Tumor Growth(1) & 14.042 & 1 & 0.000 \\
Tumor Growth(2) & 5.023 & 1 & 0.025 \\
Rh-factor & 5.960 & 1 & 0.015 \\
\hline
\end{tabular}

It is necessary to note a very important law: both transitions of the early cancer into the invasive cancer, as well as the cancer with N0 into the cancer with N1-2, have the phase character. These results testify by mathematical (HollingTenner) and imitating modeling of system "CEC-patient homeostasis" in terms of synergetics (Figs. 9, 10). This also proves the first results received earlier in the work [12]. Presence of the two phase transitions is evidently shown on Kohonen self-organizing neural networks maps (Fig. 11).

All of these differences and discrepancies were further investigated by structural equation modeling (SEPATH) as well as Monte Carlo simulation. From the data, summarized in Fig. (12) it could be recognized that the six clusters significantly predicted 5YS and LS of CECP after complete esophagogastrectomies: 1) phase transition "early-invasive CEC" ( $\mathrm{P}=0.000)$; 2) phase transition "CEC with N0-CEC with N1-2" $(\mathrm{P}=0.001) ; 3)$ cell ratio factors $(\mathrm{P}=0.000) ; 4)$ CEC characteristics $(\mathrm{P}=0.000) ; 5)$ biochemical homeostasis $(\mathrm{P}=0.003) ; 6)$ adjuvant chemoimmunotherapy $(\mathrm{P}=0.000)$ (Fig. 12). It is necessary to pay attention, that both phase transitions strictly depend on blood cell circuit $(\mathrm{P}=0.000)$, cell ratio factors $(\mathrm{P}=0.000-0.001)$, biochemical homeostasis $(\mathrm{P}=0.000)$ and hemostasis system $(\mathrm{P}=0.000-0.017)$.

\section{DISCUSSION}

Adequate treatment of CEC is extremely difficult and not yet problem solving. Firstly, the cardioesophageal cancer surgery demands virtuosous, very accurate and aggressive surgical technique, sometime multiorgans resections 


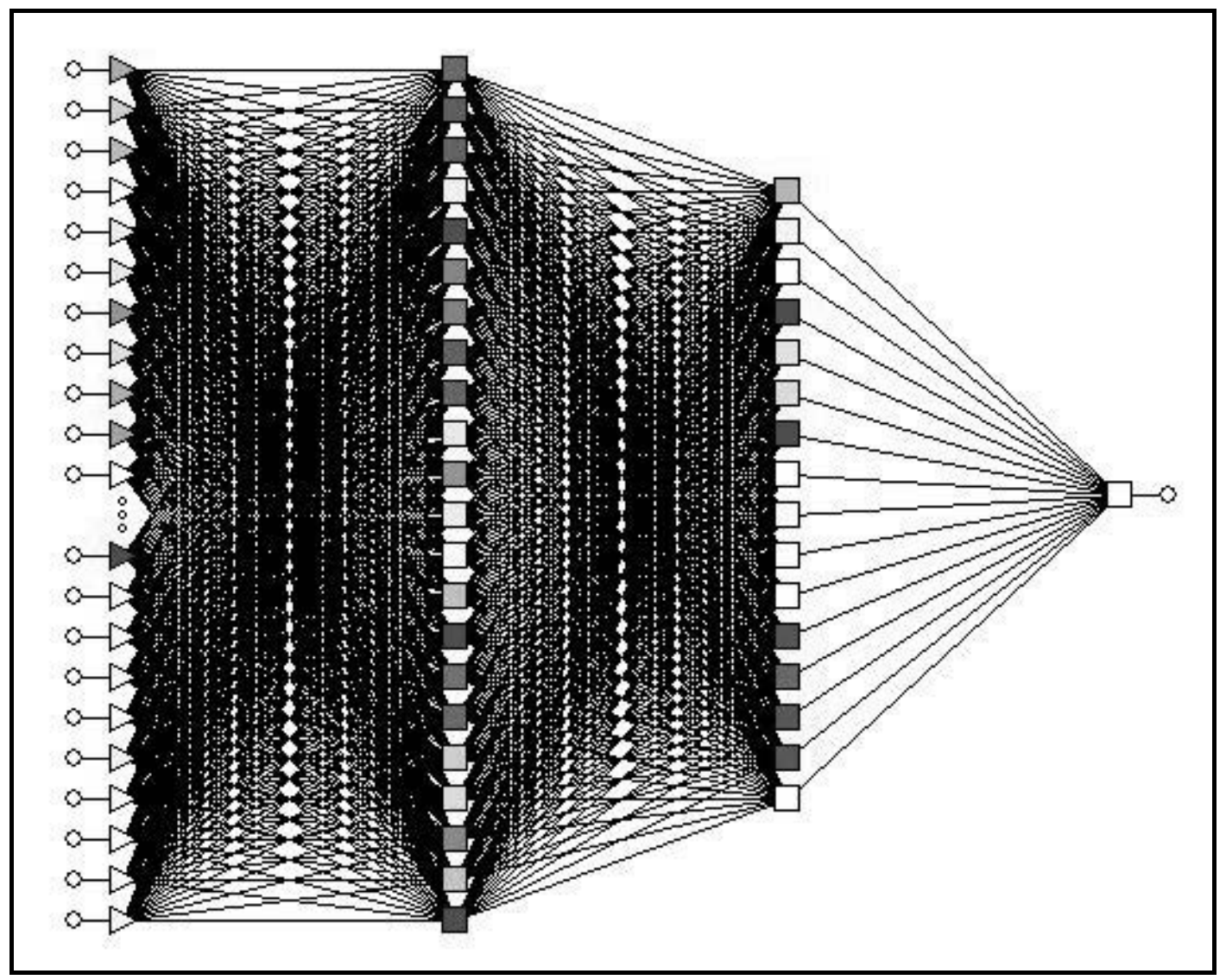

Fig. (8). Configuration of neural networks: 4-layer perceptron.

Table 2. Results of Neural Networks Computing in Prediction of 5-Year Survival of CECP After Esophagogastrectomies $(n=157: 53$ 5-Year Survivors and 104 Losses)

\begin{tabular}{|c|c|c|c|c|}
\hline \multirow{2}{*}{ NN } & \multirow{2}{*}{ Factors } & \multirow{2}{*}{ Rank } & \multirow{2}{*}{\begin{tabular}{|c|} 
Sample \\
Error
\end{tabular}} & \multirow{2}{*}{$\begin{array}{c}\mathrm{n}=\mathbf{1 5 7} \\
\text { Ratio }\end{array}$} \\
\hline & & & & \\
\hline 1 & Phase Transition "Early---Invasive Cancer" & 1 & 0.539 & $539 \mathrm{e}+7$ \\
\hline 2 & Phase Transition “N0---N1-2" & 2 & 0.426 & $426 \mathrm{e}+7$ \\
\hline 3 & Adjuvant Chemoimmunotherapy & 3 & 0.329 & $329 \mathrm{e}+7$ \\
\hline 4 & $\mathrm{~T}$ & 4 & 0.300 & $300 \mathrm{e}+7$ \\
\hline 5 & Gender & 5 & 0.285 & $285 \mathrm{E}+7$ \\
\hline 6 & Prothrombin Index & 6 & 0.176 & $176 \mathrm{e}+7$ \\
\hline 7 & Weight & 7 & 0.155 & $155 \mathrm{e}+7$ \\
\hline 8 & Glucose & 8 & 0.122 & $122 \mathrm{e}+7$ \\
\hline 9 & Age & 9 & 0.080 & $799 e+6$ \\
\hline 10 & Coagulation Time & 10 & 0.080 & $798 \mathrm{e}+6$ \\
\hline 11 & Eosinophils/Cancer Cells & 11 & 0.080 & $798 \mathrm{e}+6$ \\
\hline 12 & Erythrocytes/Cancer Cells & 12 & 0.080 & $798 \mathrm{e}+6$ \\
\hline 13 & Hemorrhage Time & 13 & 0.017 & $166 \mathrm{e}+6$ \\
\hline 14 & Protein & 14 & 0.000 & $155 \mathrm{e}+2$ \\
\hline 15 & Hemoglobin & 15 & 0.000 & 1852.5 \\
\hline 16 & Segmented Neutrophils/Cancer Cells & 16 & 0.000 & 474.43 \\
\hline \multirow[t]{2}{*}{17} & Stab Neutrophils/Cancer Cells & 17 & 0.000 & 1.323 \\
\hline & $\begin{array}{l}\text { Baseline Error } \\
\text { Area under ROC Curve } \\
\text { Correct Classification Rate (\%) }\end{array}$ & \multicolumn{3}{|c|}{$\begin{array}{c}0.0009 \mathrm{e}-12 \\
1.000 \\
100.00\end{array}$} \\
\hline
\end{tabular}

Table 3. Results of Neural Networks Genetic Algorithm Selection in Prediction of 5-Year Survival of CECP After Esophagogastrectomies $(n=157$ : 53 5-Year Survivors and 104 Losses)

\begin{tabular}{|c|l|c|}
\hline NN & \multicolumn{1}{|c|}{$\begin{array}{c}\text { CECP, } \mathbf{n}=\mathbf{1 5 7} \\
\text { Factors }\end{array}$} & $\begin{array}{c}\text { Useful for 5-Year } \\
\text { Survival }\end{array}$ \\
\hline \hline 1 & Phase Transition "N0---N1-2" & Yes \\
2 & Phase Transition "Early---Invasive Cancer" & Yes \\
3 & Adjuvant Chemoimmunotherapy & Yes \\
4 & Erythrocyte/Cancer Cells & Yes \\
5 & Leucocytes/Cancer Cells & Yes \\
6 & Eosinophils/Cancer Cells & Yes \\
7 & Segmented Neutrophils/Cancer Cells & Yes \\
8 & Healthy Cells/Cancer Cells & Yes \\
9 & Tumor Size & Yes \\
10 & T & Yes \\
11 & Hemoglobin & Yes \\
12 & Coagulation Time & Yes \\
13 & Hemorrhage Time & Yes \\
14 & Prothrombin Index & Yes \\
15 & Glucose & Yes \\
16 & Rest Nitrogen & Yes \\
17 & Bilirubin & Yes \\
18 & Gender & Yes \\
\hline
\end{tabular}


Table 4. Results of Bootstrap Simulation in Prediction of 5Year Survival of CECP After Esophagogastrectomies ( $n=157$ : 53 5-Year Survivors and 104 Losses)

\begin{tabular}{|l|c|c|c|}
\hline \multicolumn{1}{|c|}{ CECP, $\mathbf{n}=\mathbf{1 5 7}$} & Rank & $\begin{array}{c}\text { Number of } \\
\text { Samples = 3333 }\end{array}$ & \multirow{2}{*}{ P< } \\
\cline { 3 - 3 } & & Kendall'Tau-A & \\
\hline \hline Tumor Size & 1 & -0.228 & 0.000 \\
T & 2 & -0.223 & 0.000 \\
Healthy Cells/Cancer Cells & 3 & 0.215 & 0.000 \\
Erythrocytes/Cancer Cells & 4 & 0.211 & 0.000 \\
Leucocytes/Cancer Cells & 5 & 0.205 & 0.000 \\
Lymphocytes/Cancer Cells & 6 & 0.197 & 0.000 \\
Phase Transition "NO---N1-2" & 7 & -0.189 & 0.000 \\
Segmented Neutrophils/Cancer Cells & 8 & 0.189 & 0.000 \\
Thrombocytes/Cancer Cells & 9 & 0.182 & 0.000 \\
Monocytes/Cancer Cells & 10 & 0.159 & 0.01 \\
Phase Transition “Early---Invasive Cancer" & 11 & -0.144 & 0.01 \\
G & 12 & -0.137 & 0.05 \\
Eosinophils/Cancer Cells & 13 & 0.134 & 0.05 \\
Adjuvant Chemoimmunotherapy & 14 & 0.122 & 0.05 \\
Coagulation Time & 15 & -0.121 & 0.05 \\
Histology & 16 & -0.117 & 0.05 \\
Tumor Growth & 17 & -0.112 & 0.05 \\
\hline
\end{tabular}

especially for local advanced CEC for completeness (R0) and always will be the scope of activity of elite top surgeons $[2,3,11,12]$. Real surgical removal of tumor, subadjacent tissues and lymph node metastases remains the cornerstone of management of this very aggressive cancer giving the real chance for cure in spite of extensive research over the last 30 years in terms of chemotherapy, radiotherapy, immunotherapy and gene therapy $[1,3,7]$. Nevertheless, the effectiveness of radical esophagogastrectomies already reached its limit and leaves much to be desired: the average real 5-year survival rate of radically operated CECP even after combined multiorgans resections is $20-35 \%$ and practically is not improved during the last 25-30 years, as the great majority of patients has already advanced CEC. Secondly, modern rough estimated TNM-classification is based only on cancer characteristics and does not take into account at all the features of extremely complex alive supersystem - the patient's organism. From this it follows that the prediction of CEC is barely non adequate. On this point, we used complex system analysis, artificial intelligence (neural networks computing), simulation modeling and statistical methods in combination, because the different approaches yield complementary pieces of prognostic information. Great advantage of the artificial intelligence methods is the opportunity to find out hidden

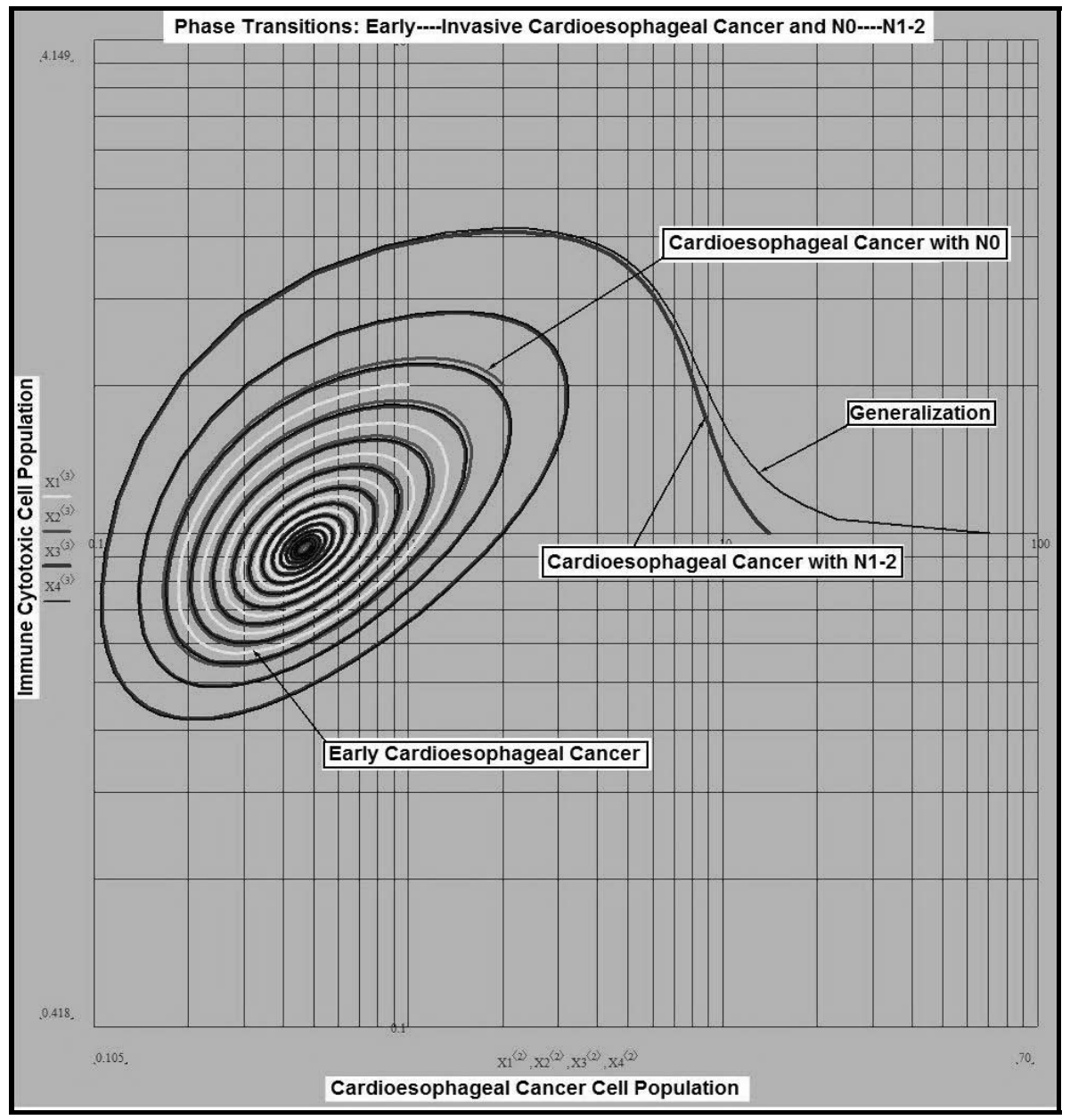

Fig. (9). Results of Holling-Tenner modeling of system "CEC-Lymphocytes" in prediction of CECP survival after esophagogastrectomies (dynamics of early cancer: Lymphocytes/Cancer Cells $=1 / 1$; dynamics of cancer with N0: Lymphocytes/Cancer Cells $=3 / 4$; dynamics of cancer with N1-2: Lymphocytes/Cancer Cells = 2/3; cancer generalization: Lymphocytes/Cancer Cells = 1/10). 


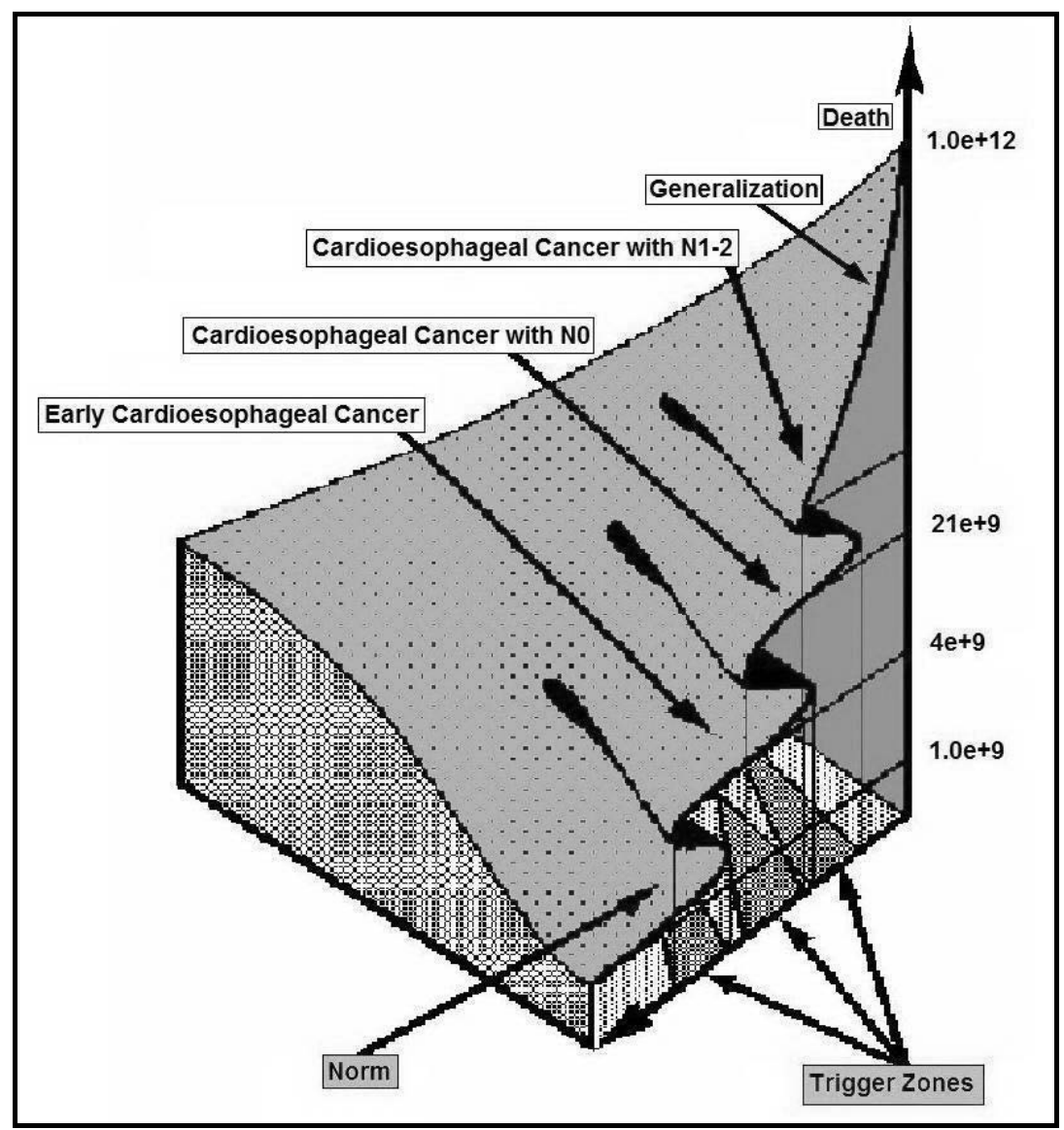

Fig. (10). Presence of the two phase transitions "early cancer-invasive cancer" and "cancer with N0-cancer with N1-2" in terms of synergetics.

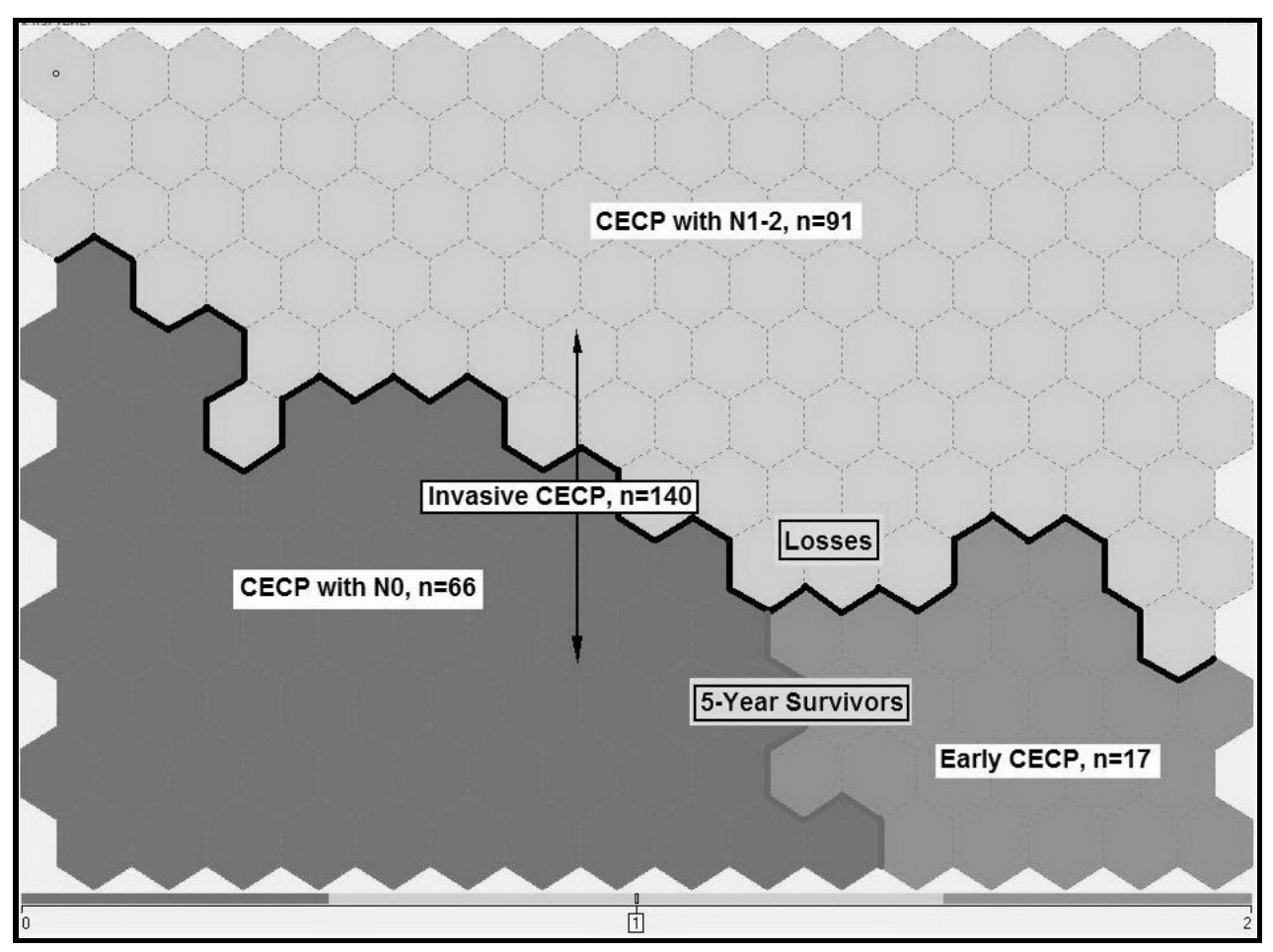

Fig. (11). Results of Kohonen self-organizing neural networks computing in prediction of CECP survival after esophagogastrectomies ( $\mathrm{n}=$ 157). The black curve line stand for 5-year survivors below and for losses above. The area under more dark-color shadow stand for CECP with N0 and the area under the weak-colored shadow stand for CECP with N1-2. The area under the less dark-color shadow stand for early CECP, the area under the weak-colored shadow and more dark-color shadow stand for invasive CECP. 


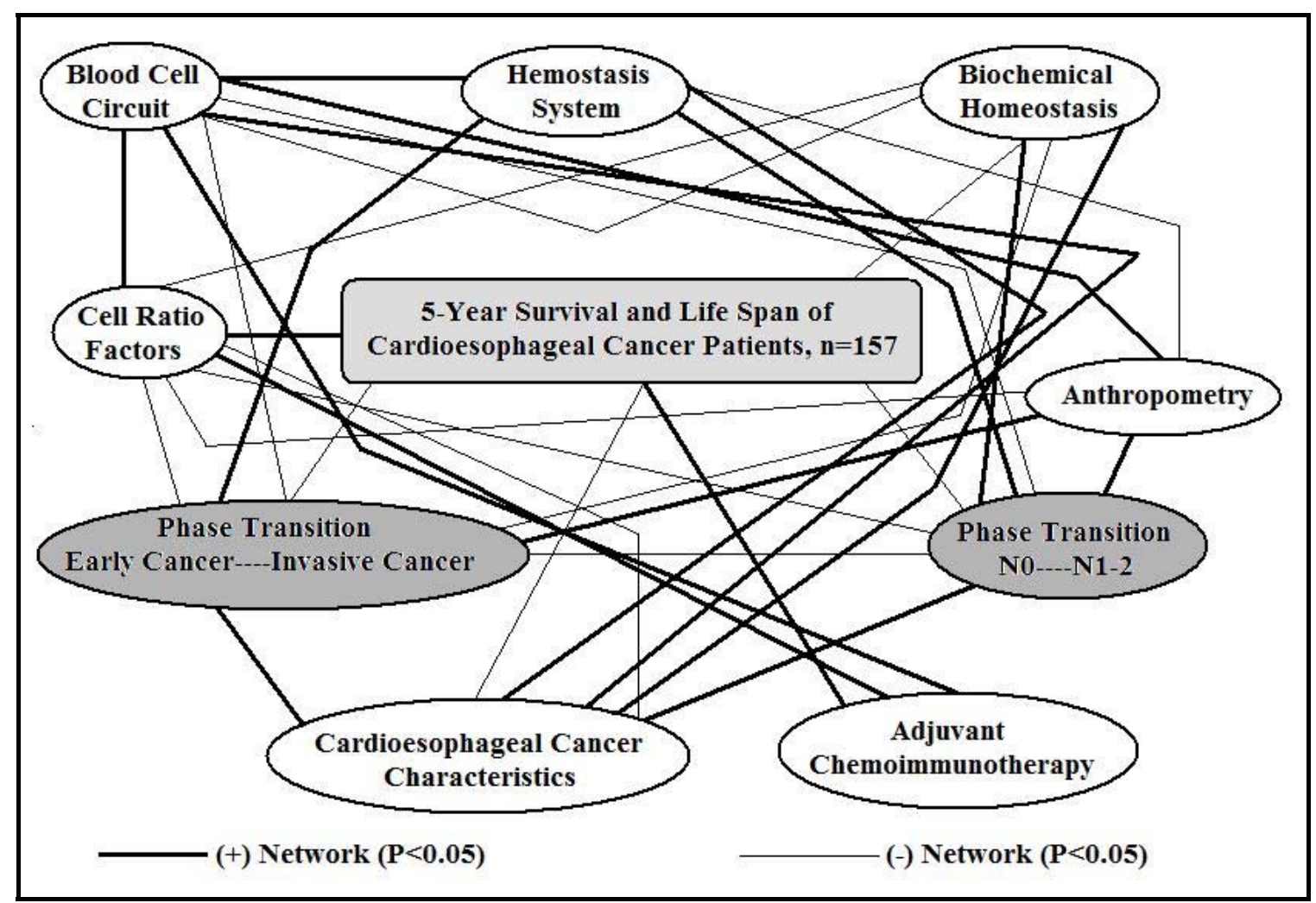

Fig. (12). Significant networks between CECP ( $\mathrm{n}=157)$ survival, cancer characteristics, blood cell circuit, cell ratio factors, hemostasis system, biochemical homeostasis, anthropometric data, phase transition "early cancer-invasive cancer", phase transition "cancer with N0-cancer with N1-2" and adjuvant chemoimmunotherapy (SEPATH network model).

interrelations which cannot be calculated by analytical and system methods. Meanwhile, huge merit of simulation modeling is the identification of dynamics of any supersystem, including alive supersystem like human homeostasis, on the hole in time [12,15-21].

For the early CEC only radical surgery is satisfactory proof: 5YS of patients with early CEC after esophagogastrectomies reaches $90-100 \%$ without adjuvant treatment. From this follows the absolute necessity of screening and early detection of CEC.

The situation becomes very complicated at once if we have local advanced CEC and, unfortunately, such patients make up the majority. Without radical procedures these CECP usually quickly die. Only world top surgeons are capable to perform such combined operations radically. In case of success $20-30 \%$ of patients with locally advanced CEC live 5 and more years $[3,8]$.

The most widely accepted treatment strategy for lymph node metastasis is the subsequent initiation of multimodality treatment, including surgery, adjuvant/neoadjuvant chemotherapy or chemoradiation $[1,14]$. At that radical surgical removal of $\mathrm{CEC}$ and lymph node metastasis plays a paramount role again, allowing to decrease sharply the number of cancer cell population in patient' organism and to warn possible deadly complications (e.g., profuse hemorrhage). Theoretically chemoimmunotherapy is the most effective when used in patients with a relatively low residual malignant cell population (approximately 1 billion cancer cells per patient) in terms of hidden micrometastasis [12]. This is typical clini- cal situation for CECP with N1-2 after radical procedures. Present research only confirmed this axiom. In the given situation high-precision prediction of CECP survival after surgery, which allows to select concrete patients for adjuvant treatment and to cut huge financial expenses, has a great value.

In conclusion, best treatment strategies for CECP are: 1) screening and early detection of CEC; 2) availability of very experienced thoracoabdominal surgeons because of complexity of radical procedures; 3) aggressive en block surgery and adequate abdominal, mediastinal, cervical lymphadenectomy for completeness; 4) high-precision prediction; 5) adjuvant chemoimmunotherapy for CECP with unfavorable prognosis.

\section{REFERENCES}

[1] Rizzetto C, DeMeester SR, Hagen JA, et al. En bloc esophagectomy reduces local recurrence and improves survival compared with transhiatal resection after neoadjuvant therapy for esophageal adenocarcinoma. J Thorac Cardiovasc Surg 2008; 35: 1228-36.

[2] DeMeester SR. Adenocarcinoma of the esophagus and cardia: a review of the disease and its treatment. Ann Surg Oncol 2006; 13(1): $12-30$

[3] Davydov MI, Ter-Ovanesov MD, Stilidi IS, et al. Cancer of the proximal section of the stomach: the standards of surgical treatment based on 30 years of experience. Vestn Ross Akad Med Nauk 2002; $1: 25-9$.

[4] Gee DW, Rattner DW. Management of gastroesophageal tumors Oncologist 2007; 12: 175-85.

[5] Siewert JR, Holscher AH, Becker K, et al. Kardiakarzinom: Versuch einer therapeutisch relevanten Klassifikation. Chirurg 1996; 58: 25-34.

[6] Siewert JR, Feith M, Werner M, Stein HJ. Adenocarcinoma of the esophagogastric junction. Results of surgical therapy based on ana- 
tomical /topographic classification in 1002 consecutive patients. Ann Surg 2000; 232: 353-61.

[7] Barbour AP, Rizk NP, Gonen M, et al. Adenocarcinoma of the gastroesophageal junction: influence of esophageal resection margin and operative approach on outcome. Ann Surg 2007; 246: 1-8.

[8] Pedrazzani C, de Manzoni G, Marrelli D, et al. Lymph node involvement in advanced gastroesophageal junction adenocarcinoma. J Thorac Cardiovasc Surg 2007; 134: 378-85.

[9] Shen KR, Cassiva St D, Deschamps C, et al. Surgical treatment of tumours of the proximal stomach with involvement of the distal esophagus: A 26-years experience with Siewert type III tumours. J Thorac Cardiovasc Surg 2006; 132: 755-62.

[10] Nakamura T, Oguma H, Sasagawa T, et al. Left thoracoabdominal approach for adenocarcinoma of the esophagogastric junction. Hepatogastroenterology 2008; 55: 1332-7.

[11] Yonemura Y, Kojima N, Kawamura T, et al. Treatment results of adenocarcinoma of the gastroesophageal junction. Hepatogastroenterology 2008; 55: 475-81.

[12] Kshivets O. Expert system in diagnosis and prognosis of malignant neoplasms. Dissertation for Sc.D. Tomsk 1995; p. 486.
[13] Morozow VG, Chavinson VC. Isolation, refinement and identification of immunomodulated polypeptide from calf and human thymus. Biochemistry 1981; 9: 1652-9.

[14] Kshivets O. Esophageal cancer: Optimization of management. Open Cardiovasc Thorac Surg J 2008; 1: 1-11.

[15] Bazykin AD. Mathematical biophysics of cooperating populations. Science: Moscow 1985; p. 181.

[16] Haken H. Information and self-organization. A macroscopic approach to complex systems. Springer: Berlin 2006; p. 240.

[17] Odom-Maryon T. Biostatistical methods in oncology. Cancer management: A multidisciplinary approach. $1^{\text {st }}$ ed. Huntington, NY: PRP Inc 1996; 788-802.

[18] Mirkin B.G. A sequential fitting procedure for linear data analysis models. J Classification 1990; 7: 167-96.

[19] Joreskog KG, Sorbom D. Recent development in structural equation modeling. J Mark Res 1982; 19: 404-16.

[20] Bostwick DG, Burke HB. Prediction of individual patient outcome in cancer: comparison of artificial neural networks and KaplanMeier methods. Cancer 2001; 91(8): 1643-6.

[21] Husmeier D. The Bayesian evidence scheme for regularizing probability-density estimating neural networks. Neural Comput 2000; 12(11): 2685-717.

(C) Oleg Kshivets; Licensee Bentham Open.

This is an open access article licensed under the terms of the Creative Commons Attribution Non-Commercial License (http://creativecommons.org/licenses/by$\mathrm{nc} / 3.0 /$ ) which permits unrestricted, non-commercial use, distribution and reproduction in any medium, provided the work is properly cited. 